\title{
Inorganic Chemistry
}

pubs.acs.org/IC

\section{Fe-TPP Coordination Network with Metalloporphyrinic Neutral Radicals and Face-to-Face and Edge-to-Face $\pi-\pi$ Stacking}

${ }_{3}$ Arkaitz Fidalgo-Marijuan, ${ }^{\dagger}$ Gotzone Barandika, ${ }^{*}, \stackrel{\dagger}{ }$ Begoña Bazán, ${ }^{\dagger}$ Miren Karmele Urtiaga, ${ }^{\dagger}$ Luis Lezama, ${ }^{\S}$ 4 and María Isabel Arriortua ${ }^{\dagger}$

$5{ }^{\dagger}$ Departamento de Mineralogía y Petrología and ${ }^{\S}$ Departamento de Química Inorgánica, Facultad de Ciencia y Tecnología,

6 Universidad del País Vasco (UPV/EHU), Apartado 644, 48080 Bilbao, Spain

7 Departamento de Química Inorgánica, Facultad de Farmacia, Universidad del País Vasco (UPV/EHU), Paseo de la Universidad 7,

801006 Vitoria-Gasteiz, Spain

ABSTRACT: Compound $\left([\mathrm{FeTPPbipy}]^{\bullet}\right)_{n}(\mathrm{TPP}=$ meso-tetraphenylporphyrin and bipy $=4,4^{\prime}$-bipyridine) is the first example of a Fe-TPP-bipy coordination network, and it consists of 1D polymers packed through face-to-face and edge-to-face $\pi-\pi$ interactions. The compound has been investigated by means of X-ray diffraction, IR, Mössbauer, UV-visible, and EPR spectroscopies, thermogravimetry, magnetic susceptibility measurements, and quantum-mechanical density functional theory (DFT) and timedependent DFT calculations. The chemical formula for this compound can be confusing because it is compatible with $\mathrm{Fe}^{\mathrm{II}}$ and $\mathrm{TPP}^{2-}$ anions. However, the spectroscopic and magnetic properties of this compound are consistent with the presence of low-spin $\mathrm{Fe}^{\mathrm{III}}$ ions and [FeTPPbipy $]^{\bullet}$ neutral radicals. These

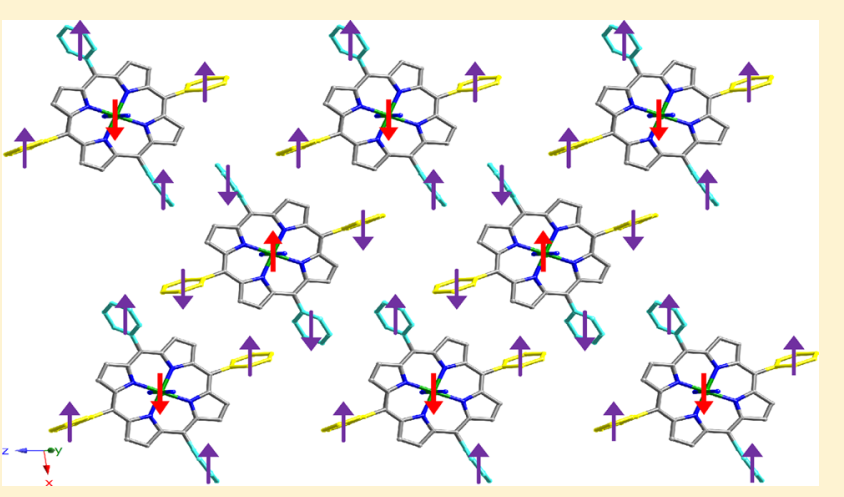
radicals are proposed to be formed by the reduction of metalloporphyrin, and the quantum-mechanical calculations are consistent with the fact that the acquired electrons are located on the phenyl groups of TPP.

26 Metalloporphyrins are one of the cornerstones on which the 27 existence of life is based because major biochemical, enzymatic, 28 and photochemical functions depend on the special properties of 29 the tetrapyrrolic macrocycle. ${ }^{1}$ Thus, porphyrin catalysts are well30 known to be highly efficient for oxidative reactions, ${ }^{2}$ and during 31 the last years, great effort has been devoted to the immobilization 32 of distinct types of catalysts on solid surfaces, ${ }^{3-5}$ with porphyrins 33 also having been investigated in this field. ${ }^{6-16}$ Thus, these com34 pounds can also be used for coordination networks where the 35 assembly of metalloporphyrinic structural units can be achieved 36 by coordination bonds and other weaker cohesion forces. ${ }^{17,18}$ 37 There are many examples of metalloporphyrinic three38 dimensional (3D) frameworks, but most of them consist of the 39 crystallization of monomeric complexes, with the cohesion forces 40 being hydrogen bonds and $\pi$ stacking. In fact, if thinking of high 41 dimensionality in terms of the formation of coordination 42 polymers, metalloporphyrins exhibit important limitations. 43 To illustrate this point, the case of meso-tetraphenylporphyrin 44 (TPP) can be cited. CSD research indicates the existence of 45 monomers, dimers, trimers, and other types of aggregates. 46 However, the highest dimensionality achieved with pyridyl 47 ligands connected on axial positions for octahedral specimens 48 corresponds to one-dimensional (1D) coordination polymers, 49 and just seven of them have been prepared so far. ${ }^{19-24}$ It is also 50 worth mentioning that none of them has iron $(\mathrm{Fe})$ as the metal center. In fact, as far as we are aware, the highest dimensionality 51 found for Fe-TPP-dipyridyl systems consists of dimers. How- 52 ever, it must be pointed out that there are two previous examples 53 in the literature for $1 \mathrm{D} \mathrm{Fe-TPP}$ polymers with cyanide-based 54 ligands. ${ }^{25,26}$

The work herein presented was inspired by previously 56 reported metalloporphyrinic frameworks exhibiting bipyridyl 57 ligands. ${ }^{27-34}$ Our intention was the synthesis of high-dimensional 58 frameworks in which metalloporphyrins play two roles: as 59 building blocks in porous networks and as catalysts immobilized in 60 the pores. We still have not achieved this goal, but instead we have 61 synthesized and characterized the compound ([FeTPPbipy $\left.]^{\bullet}\right)_{n}, 62$ where bipy is $4,4^{\prime}$-bipyridine (bipy). The compound exhibits 1D 63 coordination polymers that crystallize in a 3D framework in which 64 both face-to-face and edge-to-face $\pi$ stacking of the phenyl groups 65 provide stability to the lattice. The main interest of this com- 66 pound lies in the fact that it is the first $\mathrm{Fe}-\mathrm{TPP}$-bipy compound 67 characterized so far. Additionally, the special characteristics of 68 this compound have produced an intricate discussion based on 69 an exhaustive characterization [X-ray diffraction, IR, Mössbauer, 70 UV-visible, and EPR spectroscopies, thermogravimetry, mag- 71 netic susceptibility measurements, and quantum-mechanical 72

Received: March 26, 2013 
73 density functional theory (DFT) and time-dependent DFT 74 (TD-DFT) calculations].

\section{EXPERIMENTAL SECTION}

76 Materials. All solvents and chemicals were used as received from reliable 77 commercial sources. The reagents 5,10,15,20-tetraphenylporphinyliron(III) 78 chloride (FeTPP-Cl) and 4,4'-bipyridine (bipy; 98\%) and the solvent $79 \mathrm{~N}, \mathrm{~N}$-dimethylformamide (DMF; 99.8\%) were purchased from Sigma80 Aldrich Co.; absolute ethanol was purchased from Panreac.

81 Physicochemical Characterization Techniques. The IR spec82 trum was collected on a JASCO FT/IR-6100 spectrometer at room 83 temperature in the range of $4000-400 \mathrm{~cm}^{-1}$ in $\mathrm{KBr}$ pellets ( $1 \%$ of the 84 sample). $\mathrm{C}, \mathrm{H}$, and $\mathrm{N}$ elemental analyses were measured using a Euro EA 853000 elemental analyzer. UV-visible diffuse-reflectance measurements 86 were carried out on a Cary 5000 UV-visible-near-IR spectropho87 tometer in the range of $200-2500 \mathrm{~nm}$. Thermogravimetric analyses 88 were carried out using a NETZSCH STA 449F3 thermobalance. A 89 crucible containing $10 \mathrm{mg}$ of sample was heated at $5{ }^{\circ} \mathrm{C} \mathrm{min}^{-1}$ in the 90 temperature range of $30-500{ }^{\circ} \mathrm{C}$. Mössbauer spectra were obtained at 91 room temperature using a constant-acceleration Mössbauer spectrom92 eter with a ${ }^{57} \mathrm{Co} / \mathrm{Rh}$ source. The velocity calibration was done using a 93 metallic $\mathrm{Fe}$ foil. Electron paramagnetic resonance (EPR) spectra were 94 measured with a Bruker ESP-300 spectrometer operating at X band and 95 equipped with a nitrogen and helium cryostat. Magnetic susceptibility 96 measurements were measured in the range of 4-300 K with a Quantum 97 Design SQUID MPMS-7T magnetometer.

98 X-ray Structure Determination. Prismatic dark-blue single 99 crystals of $\left(\left[\mathrm{FeTPPbipy}^{\bullet}\right)_{n}\right.$ with dimensions given in Table 1 were

Table 1. Crystallographic Data for $\left([\mathrm{FeTPPbipy}]^{\bullet}\right)_{n}$

\begin{tabular}{ll} 
compound & $\left([\mathrm{FeTPPbipy}]^{\bullet}\right)_{n}$ \\
formula & $\mathrm{C}_{54} \mathrm{H}_{36} \mathrm{FeN}_{6}$ \\
fw, $\mathrm{g} \mathrm{mol}^{-1}$ & 824.74 \\
cryst syst & monoclinic \\
space group & $\mathrm{C} 2 / \mathrm{c}(\mathrm{No} .15)$ \\
$a, \AA$ & $21.6833(8)$ \\
$b, \AA$ & $11.0827(4)$ \\
$c, \AA$ & $17.6206(6)$ \\
$\beta$, deg & $97.354(3)$ \\
$V, \AA^{3}$ & $4199.6(3)$ \\
$Z$ & 4 \\
$\rho_{\text {obs }} \rho_{\text {cal }}, \mathrm{g} \mathrm{cm}{ }^{-3}$ & $1.309(5), 1.304$ \\
$F(000)$ & 1712 \\
$\mu$, mm & \\
crystal size, mm & 0.405 \\
abs corrn & $0.34 \times 0.077 \times 0.072$ \\
radiation $\lambda, \AA$ & analytical \\
temperature, $\mathrm{K}$ & 0.71073 \\
reflns collected, unique & $100(2)$ \\
limiting indices & $10334,3907\left(R_{\text {int }}=0.04\right)$ \\
refinement method & $-26 \leq h \leq 26,-7 \leq k \leq 13,-21 \leq l \leq 19$ \\
final $R$ indices $[I>2 \sigma(I)]^{a}$ & full-matrix least squares on $F^{2}$ \\
$R$ indices $(\text { all data })^{a}$ & $\mathrm{R} 1=0.0351, \mathrm{wR} 2=0.0714$ \\
GOF on $F^{2}$ & $\mathrm{R} 1=0.0513, \mathrm{wR} 2=0.0738$ \\
parameters $/$ restraints & 0.909 \\
$\left.{ }^{a} \mathrm{R} 1=\left[\left(\left|F_{\mathrm{o}}\right|-\mid F_{\mathrm{c}}\right)\right] / \mid F_{\mathrm{o}} \mathrm{l} . \mathrm{wR} 2=\left[w\left|F_{\mathrm{o}}\right|^{2}-\left|F_{\mathrm{c}}\right|^{2}\right)^{2}\right] /\left[w\left(\left|F_{\mathrm{o}}\right|^{2}\right)^{2}\right]^{1 / 2}$. \\
\hline
\end{tabular}

100 selected under a polarizing microscope and mounted on MicroMounts. 101 Single-crystal X-ray diffraction data were collected at $100 \mathrm{~K}$ on an 102 Xcalibur 2 automatic diffractometer with graphite-monochromated Mo $103 \mathrm{~K} \alpha$ radiation $(\lambda=0.71073 \AA)$. The Lorentz polarization and absorption 104 corrections were made with the diffractometer software, taking into 105 account the size and shape of the crystals. ${ }^{35}$ The structure was solved 106 in the monoclinic space group $C 2 / c$ by direct methods with the 107 SHELXS-97 program. ${ }^{36}$ Refinement of the crystal structure was performed by full-matrix least squares based on $F^{2}$, using the 108 SHELXL-97 program. ${ }^{36}$ Anisotropic thermal parameters were used for 109 all non-H atoms (Figure S1, Supporting Information). All $\mathrm{H}$ atoms 110 connected to the aromatic rings ( $\mathrm{C}-\mathrm{H} 0.95 \AA$ ) were fixed geometrically 111 and were refined using a riding model with common isotropic dis- 112 placements. Brief crystal data are listed in Table 1. (See Tables S1-S4, 113 Supporting Information, for bond distances and angles, atomic 114 coordinates, and anisotropic displacement.)

\section{RESULTS AND DISCUSSION}

116

Synthesis of ([FeTPPbipy $\left.]^{\bullet}\right)_{n}$. FeTPP-Cl (7 mg, $\left.0.01 \mathrm{mmol}\right), 117$ bipy (9.4 mg, $0.06 \mathrm{mmol}$ ), and $40 \mu \mathrm{L}$ of $\mathrm{NaOH}(3 \mathrm{M})$ were added 118 to a mixture of DMF $(3 \mathrm{~mL})$ and ethanol $(1 \mathrm{~mL})$ in a small 119 capped vial, sonicated to ensure homogeneity, and heated to 120 $120{ }^{\circ} \mathrm{C}$ for $48 \mathrm{~h}$, following by slow cooling to room temperature 121 at $2{ }^{\circ} \mathrm{C} \mathrm{h}^{-1}$, yielding diffraction-quality dark-blue prismatic 122 crystals. Anal. Calcd for $\mathrm{C}_{54} \mathrm{H}_{36} \mathrm{FeN}_{6}$ : C, 78.64; H, 4.39; N, 123 $10.18 \%$. Found: C, 78.45(8); H, 4.31(10); N, 9.86(6). $\nu_{\max } / \mathrm{cm}^{-1}: 124$ 3051, 3022, and $2964\left[\mathrm{C}\left(\mathrm{sp}^{2}\right) \mathrm{H}\right], 1600-1440$ (CC), $1348(\mathrm{CN}), 125$ 1204 and 1070 (bipy), 1000 (FeTPP), $750(\mathrm{CH})$ (Figure S2, 126 Supporting Information).

127

Crystal Structure. The crystal structure of $\left([\text { FeTPPbipy }]^{\bullet}\right)_{n} 128$ was determined by means of single-crystal X-ray diffraction. The 129 structure consists of $1 \mathrm{D}$ coordination polymers extending 130 along the [010] direction, where metalated porphyrins are 131 axially bonded to two bipy ligands (Figure 1). 132

The resulting octahedral coordination sphere exhibits bond 133 angles and distances that are typical for these types of com- 134 pounds (Table 2). ${ }^{37}$ These coordination polymers crystallize 135 as shown in Figure 2. The connections between chains take place 136 through edge-to-face $\pi$ stacking along the [10-1] direction 137 (centroid-to-centroid distance of $3.662 \AA$ and angle of $83.94^{\circ}$ ). 138 Additionally, there is a face-to-face $\pi$ stacking along the [101] 139 direction (centroid-to-centroid distance 5.067 $\AA$ and angle 140 $0.02^{\circ}$ ). Therefore, the cohesion between $1 \mathrm{D}$ coordination poly- 141 mers is based on a robust network of $\pi$ bonds.

142

In principle, the chemical formula could be interpreted in 143 terms of the presence of $\mathrm{Fe}^{\mathrm{II}}$ and $\mathrm{TPP}^{2-}$ ions. However, as ex- 144 plained below, the behavior of $\left([\mathrm{FeTPPbipy}]^{\bullet}\right)_{n}$ is consistent 145 with the presence of $\mathrm{Fe}^{\mathrm{III}}$. Therefore, because no further de- 146 protonation is observed for the organic ligands, reduction of 147 $\mathrm{TPP}^{2-}$ must be assumed to maintain neutrality. ${ }^{38,39}$

148

Distortion of the porphyrin was analyzed by the normal- 149 coordinate structural decomposition method developed by 150 Shelnutt et al., ${ }^{40,41}$ indicating a low saddle-type distortion 151 $\left(s a d, \mathrm{~B}_{2 \mathrm{u}}\right)$. The contribution of this type of distortion (0.5967) to 152 the total displacements is $67 \%$, a, usual feature on low-spin 153 iron(III) porphyrins. ${ }^{42}$

It is worth mentioning that, as far as we are aware, $\left([\text { FeTPPbipy }]^{\bullet}\right)_{n} 155$ is the first Fe-TPP-dipyridyl coordination network exhibiting ID 156 polymers, and it has been formed by the assembly of neutral radical 157 units. More details about the latter will be discussed below. 158

Purity of the Measured Samples. In order to determine 159 the purity of the samples used for further characterization, the 160 grinding effect on single crystals has been evaluated by means of 161 X-ray diffraction. The results (Figure S3, Supporting Informa- 162 tion) indicate that a significant rate of amorphization takes place. 163 Taking this into consideration, magnetic susceptibility measure- 164 ments and UV-visible spectroscopy were performed by using 165 nonground single crystals introduced into a capillary in order to 166 guarantee the purity of the sample. Unfortunately, the crystal 167 features for $\left([\mathrm{FeTPPbipy}]^{\bullet}\right)_{n}$ were absolutely inadequate for the 168 




Figure 1. 1D coordination polymers extending along the $[010]$ direction for $\left([\text { FeTPPbipy }]^{\bullet}\right)_{n}$. Color code: green, Fe; blue, N; gray, yellow, turquoise, $\mathrm{C}$ (porphyrin); purple, C(bipy). $\mathrm{H}$ atoms are omitted for clarity.

Table 2. Selected Bond Angles (deg) and Distances $(\AA)$ for $\left([\text { FeTPPbipy }]^{\bullet}\right)_{n}(\text { Distances in Bold })^{a}$

\begin{tabular}{|c|c|c|c|c|c|c|}
\hline \multicolumn{7}{|c|}{ Octahedron $\left[\mathrm{FeN}_{6}\right]$} \\
\hline $\mathrm{Fe}$ & $\mathrm{N} 1$ & $\mathrm{~N} 1^{\mathrm{i}}$ & $\mathrm{N} 2$ & $\mathrm{~N} 2^{\mathrm{i}}$ & N3 & N4 \\
\hline N4 & $88.46(4)$ & $88.46(4)$ & $91.16(4)$ & $91.16(4)$ & 180 & $1.998(2)$ \\
\hline N3 & $91.54(4)$ & $91.54(4)$ & $88.84(4)$ & $88.84(4)$ & $1.985(2)$ & \\
\hline $\mathrm{N} 2^{\mathrm{i}}$ & $90.14(6)$ & $89.92(6)$ & $177.69(8)$ & $1.996(1)$ & & \\
\hline $\mathrm{N} 2$ & $89.92(6)$ & $90.14(6)$ & $1.996(1)$ & & & \\
\hline$N 1^{\mathrm{i}}$ & $176.93(8)$ & $1.983(1)$ & & & & \\
\hline N1 & $1.983(1)$ & & & & & \\
\hline
\end{tabular}

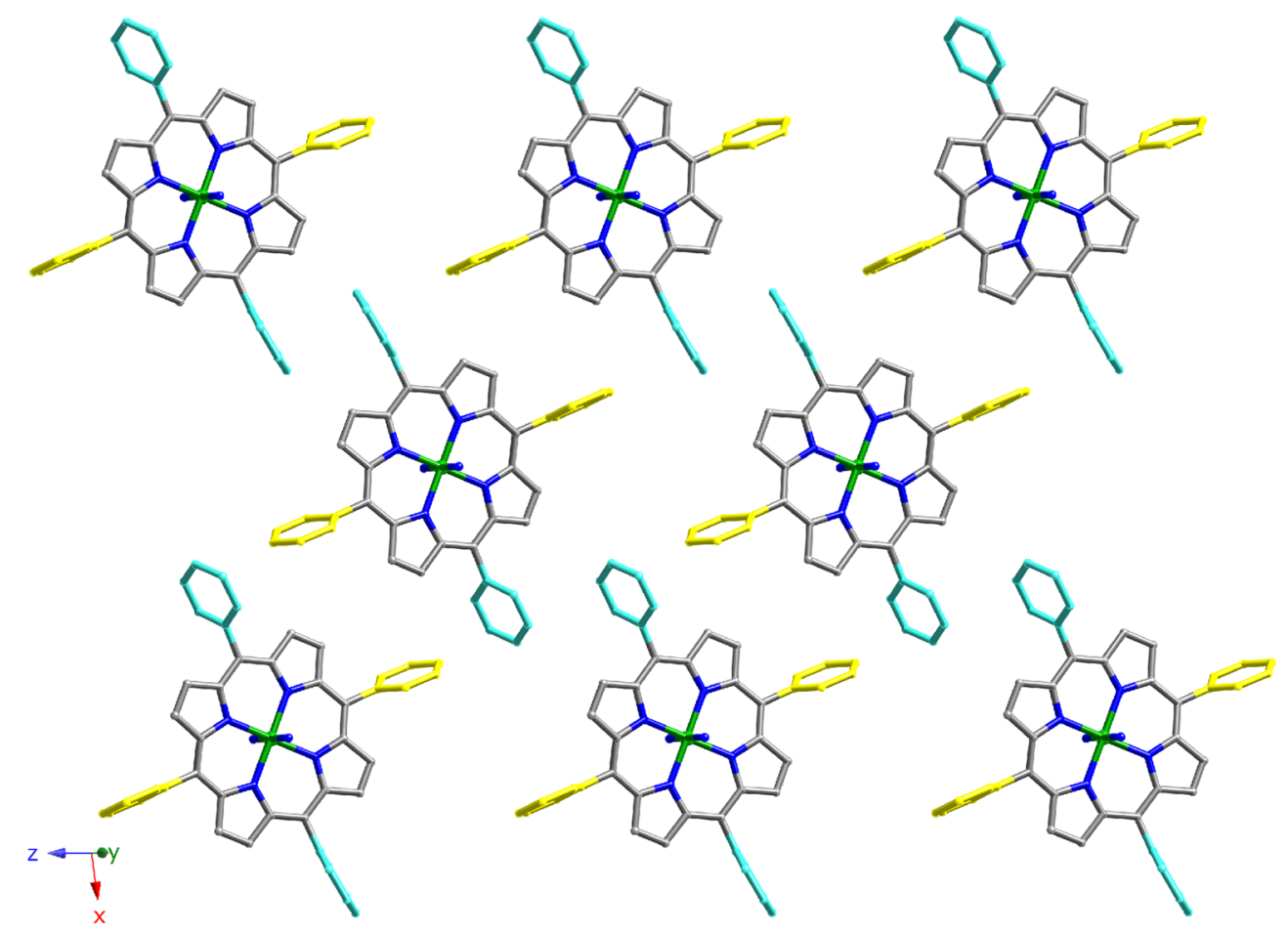

Figure 2. View of a (101) plane for $\left([\mathrm{FeTPPbipy}]^{\bullet}\right)_{n}$. Color codes are the same as those in Figure 1. The bipy ligands and $\mathrm{H}$ atoms are omitted for clarity. Face-to-face $\pi$ stacking occurs between the turquoise phenyl groups, and edge-to-face $\pi$ stacking occurs between the turquoise and yellow phenyl groups.

169 performance of EPR and Mössbauer spectroscopies on single 170 crystals.
UV-Visible (Diffuse-Reflectance) Spectroscopy. UV- 171 visible spectroscopy was performed on nonground single 172 
173 crystals, and as observed in Figure 3a, the spectrum exhibits 174 a Soret band $(\gamma)$ at $377 \mathrm{~nm}$ and $\mathrm{Q}$ bands $(\beta$ and $\alpha)$ at 517 and
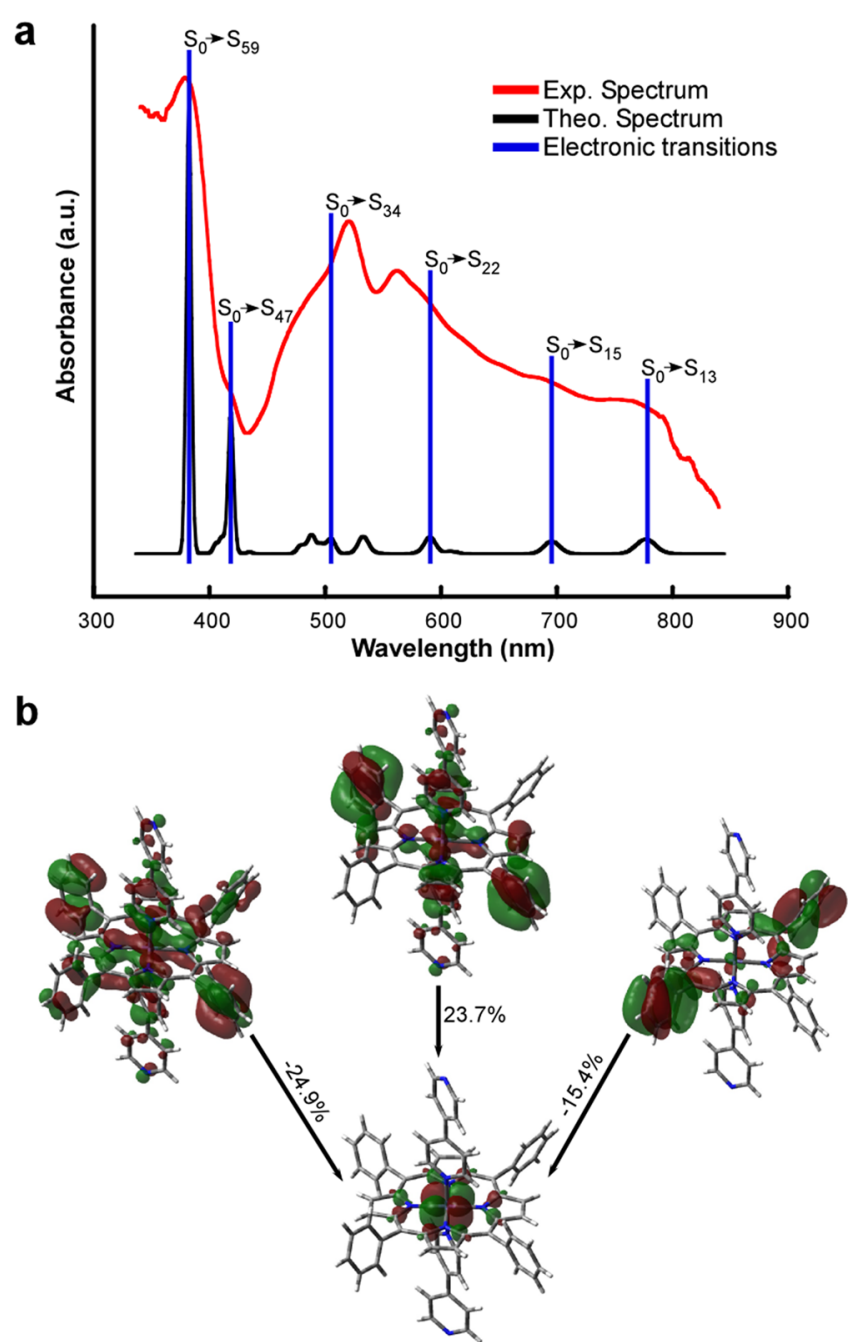

Figure 3. (a) Experimental and theoretical UV-visible spectra for $\left([\text { FeTPPbipy }]^{\bullet}\right)_{n}$ and (b) molecular orbitals involved in the $S_{0}-S_{59}$ transition.

$175557 \mathrm{~nm}$, respectively. The fact that the Soret band is blue-shifted 176 and reduced in intensity compared to typical six-coordinate low177 spin ferric porphyrin complexes 25,43 is justified by assuming the 178 presence of a radical species. ${ }^{44,45}$ The low-spin iron(III) por179 phyrin characteristic $L_{1}$ and $L_{2}$ bands ${ }^{46}$ appear at $815(\mathrm{sh})$ and $180770 \mathrm{~nm}$, respectively. A broad and weak band at $690 \mathrm{~nm}$ is in 181 accordance with the presence of a porphyrinic radical. ${ }^{44}$ These 182 results were compared with the theoretical spectra (Figure 3a) 183 obtained by TD-DFT calculations, performed by means of 184 Gaussian $03^{47}$ (B3LYP ${ }^{48,49}$ functional and 6-31G valence). In 185 addition to the good concordance between both spectra, the 186 most remarkable fact is that the molecular orbitals involved in the 187 Soret transition $\left(S_{0}-S_{59}\right)$ represent an important charge transfer 188 between the phenyl rings and the metal center (Figure $3 \mathrm{~b}$ ). This 189 fact will be mentioned below during a discussion of the magnetic 190 behavior.

191 EPR. X-band EPR spectroscopy was performed on ground 192 single crystals of $\left([\text { FeTPPbipy }]^{\bullet}\right)_{n}$. As observed, the spectrum 193 shows two signals (Figure 4). The weakest of them (with $g$ close 194 to 6) is typical for magnetically isolated Fe ${ }^{\text {III }}$ systems in axial

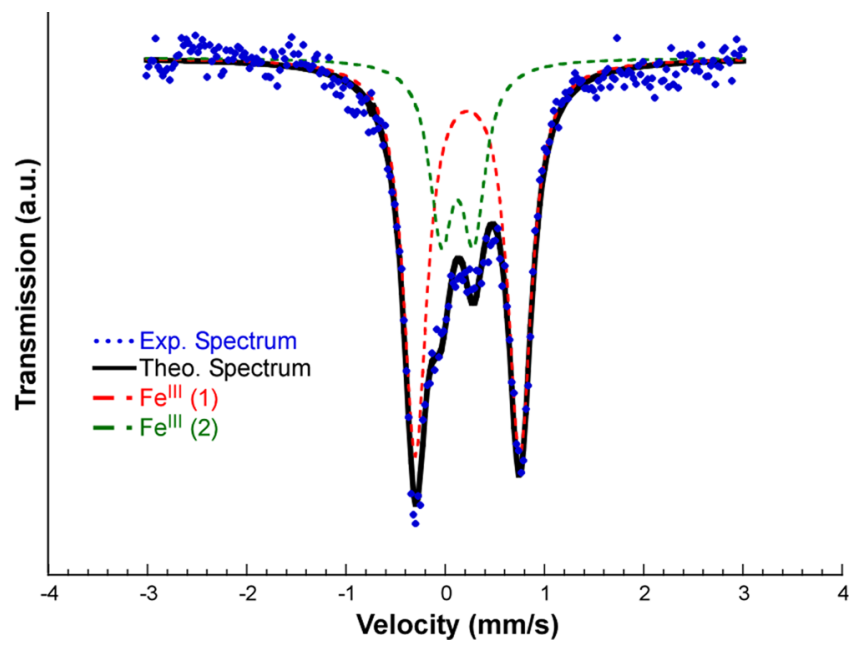

Figure 4. X-band EPR spectrum (room temperature) for ([FeTPPbipy $\left.]^{\bullet}\right)_{n}$.

symmetry. Therefore, it is supposed to have been formed by 195 crystal grinding. Unfortunately, the fact that grinding produces 196 amorphization (Figure S3, Supporting Information) results in 197 the impossibility of identifying this second phase by X-ray 198 diffraction.

On the other hand, the principal signal (with $g$ close to 2) can 200 be interpreted in terms of the following two possibilities: (a) 201 high-spin $\mathrm{Fe}^{\mathrm{III}}$ ions in very low concentration in relation to the 202 bulk of the analyzed sample and (b) low-spin Fe $\mathrm{Fe}^{\mathrm{III}}$ ions with 203 either significant magnetic interactions between metal centers 204 having different orientations or interactions with free radicals. 205 In the latter case, radicals should be either delocalized or localized 206 in such a way that they could relax in a short period of time. The 207 first hypothesis does have a sense just for the case of high-spin 208 $\mathrm{Fe}^{\mathrm{III}}$ ions diluted in a low-spin $\mathrm{Fe}^{\mathrm{II}}$ framework. This means that 209 compound ([FeTPPbipy $\left.]^{\bullet}\right)_{n}$ should contain $\mathrm{Fe}^{\mathrm{II}}$ ions and that 210 there are three contributions to the signal: the compound itself, 211 the amorphous secondary phase, and a third unknown com- 212 pound. This hypothesis has been discarded by X-band EPR 213 spectroscopy at $100 \mathrm{~K}$ (Figure S4, Supporting Information) 214 because it shows a broadening of the signal and a rapid decrease 215 of the intensity (it mostly disappears below $50 \mathrm{~K}$ ). This clearly 216 indicates the presence of antiferromagnetic interactions, there- 217 fore pointing to the second explanation. Thus, the second ex- 218 planation could just be feasible if the presence of free electrons is 219 admitted because the structural characteristics of $\left([\text { FeTPPbipy }]^{\bullet}\right)_{n} 220$ are not compatible with significant magnetic interactions between 221 metal centers (the magnetic paths through the bipy ligands are 222 too long). As explained below, these magnetic interactions were 223 analyzed through measurements of the magnetic susceptibility 224 and by DFT calculations.

225

Mössbauer Spectroscopy. Mössbauer spectroscopy was 226 performed on ground single crystals. The spectrum has been 227 simulated with the NORMOS program ${ }^{50}$ and indicates the 228 presence of two doublets: both of them corresponding to $\mathrm{Fe}^{\mathrm{III}} 229$ signals. The presence of two $\mathrm{Fe}^{\mathrm{III}}$ centers has been explained already 230 in the EPR section, and it has been associated with amorphization of 231 the sample as a consequence of the grinding, discarding the presence 232 of a previous impurity.

The most significant signal is assigned to the metal ions in 234 $\left([\mathrm{FeTPPbipy}]^{\circ}\right)_{n}$, while the second one is assumed to be due to 235 the secondary phase coming from grinding. Quantitative analysis 236 reveals that the sample contained $70.5 \%$ by weight correspond- 237 ing to $\left([\text { FeTPPbipy }]^{\bullet}\right)_{n}$. This is in accordance with the significant 238 
239 rate of amorphization observed by X-ray diffraction (Figure S3, 240 Supporting Information). Isomer shift $(\delta)$ and quadrupolar 241 splitting $(\Delta E)$ values are $0.337(1)$ and $1.054(2)$ for the first 242 signal and $0.235(2)$ and $0.326(7)$ for the second one, in the range 243 usually observed for $\mathrm{Fe}^{\mathrm{III}}$ ions (Figure 5).

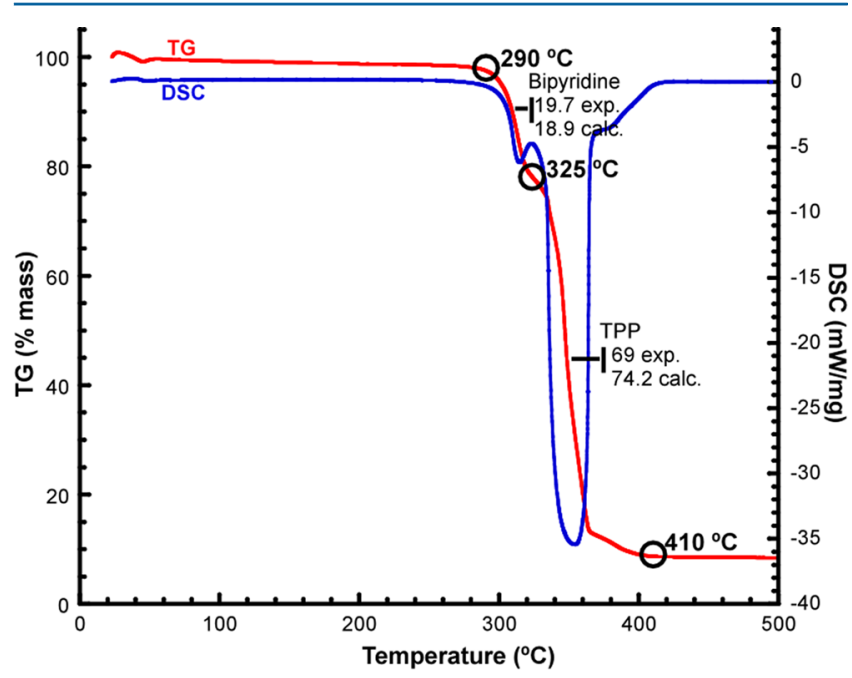

Figure 5. Mössbauer spectra for $\left([\text { FeTPPbipy }]^{\bullet}\right)_{n}$.

244 Thermogravimetry. Thermogravimetry analysis was carried 245 out on nonground single crystals. The thermogravimetric de246 composition curve of the compound shows an overlapped two247 stage mass loss, from approximately 290 to $410{ }^{\circ} \mathrm{C}$. As shown in 248 Figure 6, the first step occurs between 290 and $325^{\circ} \mathrm{C}$ with a

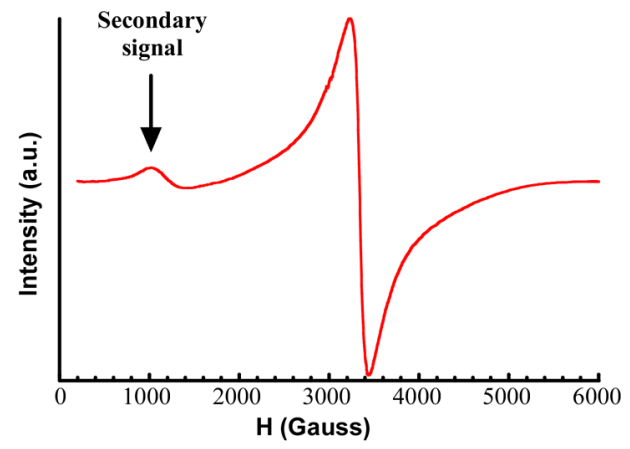

Figure 6. Thermal analysis for $\left([\mathrm{FeTPPbipy}]^{\bullet}\right)_{n}$.

$24919.7 \%$ weight loss and the second step from 325 to $410{ }^{\circ} \mathrm{C}$ with 250 a $69 \%$ weight loss. These mass percentages are close to the 251 theoretical percentages of bipyridine (18.9\%) and TPP (74.2\%) 252 molecules. The calcination product was identified by powder $253 \mathrm{X}$-ray diffraction analysis, and it consists of $\mathrm{Fe}_{2} \mathrm{O}_{3}$ [space group $254 R \overline{3} c, a=5.0248 \AA, c=13.7163 \AA$, and $\left.\gamma=120^{\circ}\right]^{5}$.

255 Magnetic Measurements. We have also performed mag256 netic susceptibility $\left(\chi_{\mathrm{m}}\right)$ measurements for $\left([\text { FeTPPbipy }]^{\bullet}\right)_{n}$ in 257 the range $4-300 \mathrm{~K}$ (Figure 7 ). It is worth mentioning that non258 ground single crystals were used for this analysis, but the original 259 crystals were introduced into a capillary. The $\chi_{\mathrm{m}} T$ value at room 260 temperature is $0.30 \mathrm{~cm}^{3} \mathrm{~K} \mathrm{~mol}^{-1}$, which is much lower than the $2614.37 \mathrm{~cm}^{3} \mathrm{~K} \mathrm{~mol}^{-1}$ value expected for a high-spin $\mathrm{Fe}^{\mathrm{III}}$ compound. 262 On the contrary, it is close to the $0.37 \mathrm{~cm}^{3} \mathrm{~K} \mathrm{~mol}^{-1}$ value 263 expected for low-spin $\mathrm{Fe}^{\mathrm{III}}$ complexes. As explained below (DFT 264 calculations), the one-electron reduction of metalloporphyrin is 265 analyzed, with the acquired electrons having been determined to



Figure 7. Thermal evolution of $\chi_{\mathrm{m}} T$ and $\chi_{\mathrm{m}}{ }^{-1}$ for $\left([\text { FeTPPbipy }]^{\bullet}\right)_{n}$ and the corresponding theoretical Curie-Weiss law (red line).

be located on the phenyl groups. On the other hand, TD-DFT 266 calculations carried out to analyze the UV-visible spectroscopy 267 (Figure $3 \mathrm{~b}$ ) indicate that there is an important charge transfer 268 between the phenyl rings and metal centers (Figure 3b). Thus, 269 the slight discrepancy between the expected $\left(0.30 \mathrm{~cm}^{3} \mathrm{~K} \mathrm{~mol}^{-1}\right) 270$ and observed $\left(0.37 \mathrm{~cm}^{3} \mathrm{~K} \mathrm{~mol}^{-1}\right) \chi_{\mathrm{m}} T$ values for low-spin $\mathrm{Fe}^{\mathrm{III}} 271$ can be explained if considering this charge transfer. 272

The thermal evolution of the reciprocal susceptibility follows 273 the Curie-Weiss law with $C_{\mathrm{m}}=0.32 \mathrm{~cm}^{3} \mathrm{~K} \mathrm{~mol}^{-1}$ and $\theta=-18.7 \mathrm{~K} 274$ (Figure 7). The product $\chi_{\mathrm{m}} T$ continuously decreases upon 275 cooling, reaching a value of $0.09 \mathrm{~cm}^{3} \mathrm{~K} \mathrm{~mol}^{-1}$ at $5.0 \mathrm{~K}$, indicating 276 the presence of antiferromagnetic interactions, as expected from 277 EPR characterization. As mentioned, these interactions cannot 278 be attributed to magnetic exchange between metal centers. There- 279 fore, coupling between metal ions and free electrons should be 280 admitted.

281

DFT Calculations. As previously mentioned, the structural 282 characterization of this compound could make one think that 283 the metal ion is $\mathrm{Fe}^{\mathrm{II}}$, in accordance with the presence of $\mathrm{TPP}^{2-} 284$ ligands and neutral bipy molecules. However, the commercial 285 reactant, $[\mathrm{FeTPPCl}]$, contains $\mathrm{Fe}^{\mathrm{III}}$, and its reduction to $\mathrm{Fe}^{\mathrm{II}}$ does 286 not seem to be feasible. On the other hand, the bond distances 287 and angles are typical for iron(III) porphyrins, and the rest of the 288 characterization techniques clearly indicate that the metal ion is $\mathrm{Fe}^{\mathrm{III}} .289$ Therefore, the best of our hypothesis is that the compound has been 290 formed by the assembly of [FeTPP] ${ }^{\bullet}$ radical structural units, which 291 extend, producing 1D polymers by means of the axial coordination 292 of the metal center to bipy ligands. Thus, the [FeTPP $]^{\bullet}$ structural 293 units should be thought of as being the result of one-electron 294 reduction of the metalloporphyrin (reactions 1 and 2).

$$
\begin{aligned}
& {[\mathrm{FeTPPC} 1] \rightarrow[\mathrm{FeTPP}]^{+}+\mathrm{Cl}^{-}} \\
& {[\mathrm{FeTPP}]^{+}+\mathrm{e}^{-} \rightarrow[\mathrm{FeTPP}]^{\bullet}}
\end{aligned}
$$

Admitting that reduction must have taken place for the metallo- 298 porphyrin, we tried to identify the reductant agent. Even if there 299 are some calculated redox potentials in the literature, ${ }^{52}$ they are 300 not useful in our case because of the nonstandard conditions 301 for solvothermal synthesis. Even so, there are several possible 302 reductant agents like residues of bipy and DMF. ${ }^{53} 303$

Thus, next question about $\left([\text { FeTPPbipy }]^{\bullet}\right)_{n}$ consists of deter- 304 mining the localization of the electron providing the metal- 305 loporphyrins with its radical nature. In the case of $\left([\text { FeTPPbipy }]^{\bullet}\right)_{n}, 306$ the presence of low-spin $\mathrm{Fe}^{\mathrm{III}}$ and an extra unpaired electron should 307 result in two unpaired electrons per metalloporphyrin. Therefore, 308 we could think of two explanations. As previously proposed, ${ }^{54} 309$ the extra unpaired electron could be delocalized on the aromatic 310 
Scheme 1. Possibilities for the Number of Unpaired Electrons Depending on the Occurrence of Antiferromagnetic Coupling through $\pi$ Stacking

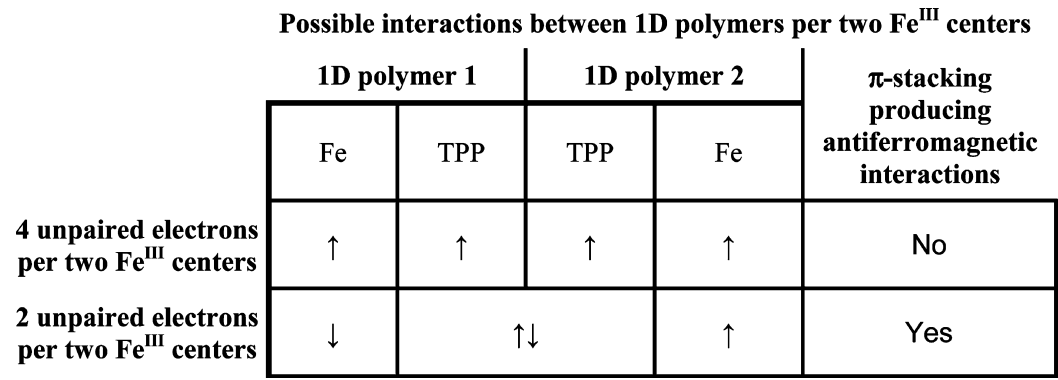

311 porphyrinic system. If analysis of the compound is done from the 312 point of view of isolated structural units (1D polymers), this 313 could be an effective explanation. However, magnetic measure314 ments are not consistent with the latter. Besides, there is an 315 intricate $\pi$-stacking system in $\left([\mathrm{FeTPPbipy}]^{\bullet}\right)_{n}$ according to 316 which analysis of the framework from such a point of view does 317 not seem to be adequate. Thus, a second explanation is that the 318 electrons acquired by reduction are paired in the $3 \mathrm{D}$ frame319 work (Scheme 1 ). This idea is strongly supported by $\pi$ stacking 320 because it provides the opportunity of electron coupling.

321 In order to provide theoretical support to the above322 mentioned aspects, both hypotheses were analyzed by means 323 of quantum-mechanical DFT calculations (Gaussian 03 program). ${ }^{47}$ 324 Calculations were performed using Becke's three-parameter hybrid 325 functional with the correlation functional of Lee, Yang, and Parr 326 (B3LYP $)^{48,49}$ with a split-valence basis set of 6-31G. This functional 327 does not consider the dispersive interactions. However, it has been 328 selected because our objective was not obtaining an accurate value for 329 the energy but representative values for a comparison between both 330 hypotheses. In fact, the goal was to investigate the effect of $\pi$ stacking 331 on the stability of the framework. To this purpose, two dimeric 332 fragments $\left.(\mathrm{FeTPPbipy})_{2}\right)_{2}$ were selected. In dimer 1 , the interdimer 333 connection is due to the edge-to-face $\pi$ bond along the [10-1] 334 direction, while in dimer 2 , the connection takes place by the face-to335 face $\pi$ bond along the [101] direction (Figure 8a). For each dimer, 336 two calculations (Table 3) were carried out: in calculation 1, the 337 dimer has four unpaired electrons (two per monomer), and in 338 calculation 2, the dimer has two unpaired electrons (one per 339 monomer). Therefore, calculation 1 accounts for the first hypothesis 340 (that is, analysis from the point of view of isolated $1 \mathrm{D}$ polymers), 341 while calculation 2 explores the possibility of electron coupling 342 through interpolymer $\pi$ stacking. Obviously, extension of the 343 framework through the three directions of space should have 344 been considered for more accurate calculations. However, the 345 large amount of atoms involved makes this very expensive.

346 Table 3 summarizes the as-calculated values. As observed, the 347 values show that for both dimers the situation with one unpaired 348 electron per monomer (two per dimer) is more stable than the 349 situation with two unpaired electrons per monomer (four per 350 dimer), supporting the idea that $\pi$ stacking is responsible for 351 stabilization of the framework.

352 At this point of the discussion, claiming that $\pi$ stacking is 353 responsible for stabilization of the framework seems to be 354 obvious. Nevertheless, the remarkable point is that calculations 355 strongly support the idea that the extra electrons have not been 356 delocalized on the TPP pyrrolic system but they are paired in 357 molecular orbitals formed by $\pi$ stacking. In fact, as observed in 358 Figure 8b,c, the calculations provided molecular orbitals for these 359 interactions.

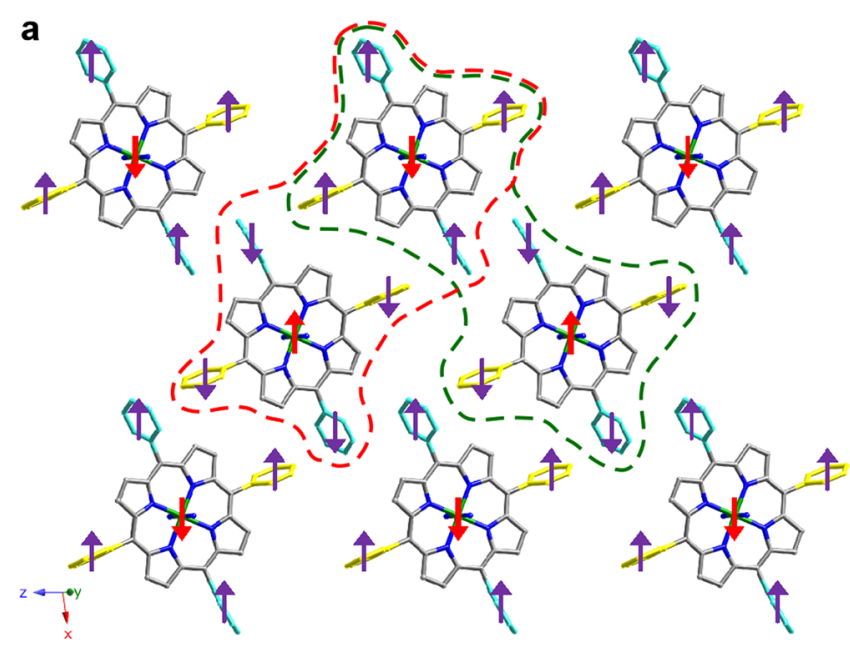

b
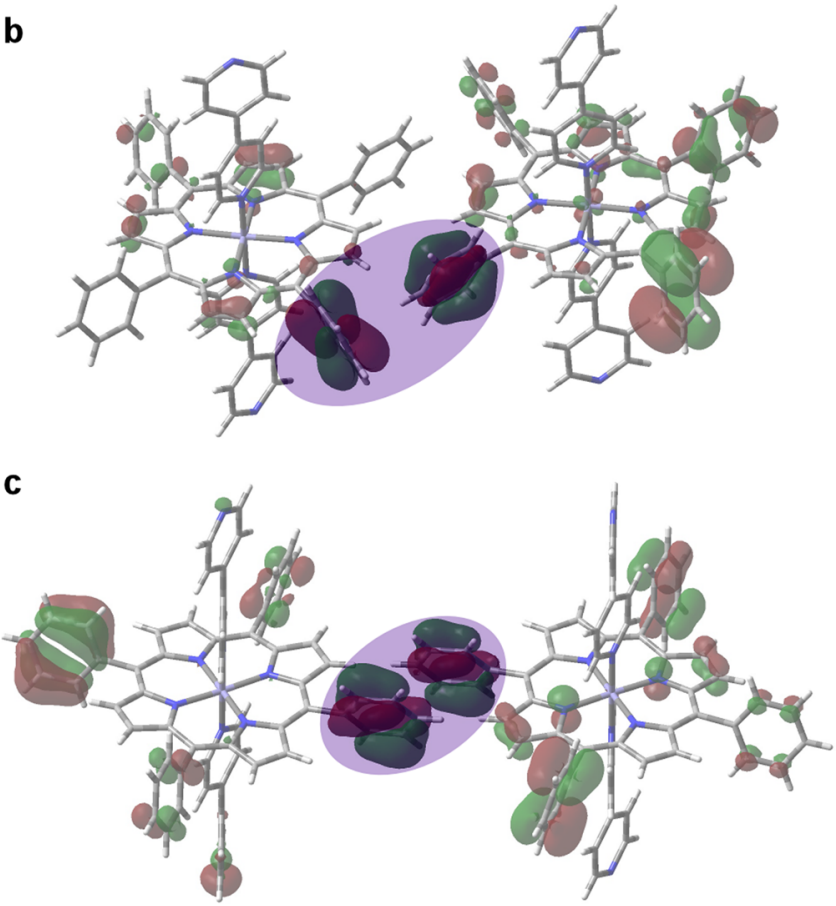

Figure 8. (a) Selected dimeric fragments for the DFT calculations according to edge-to-face (red line) and face-to-face (green line) $\pi$ interactions. A scheme for the spin distribution proposal is also shown: red arrows are the unpaired electrons corresponding to low-spin $\mathrm{Fe}^{\mathrm{III}}$ $\left(\mathrm{d}^{5}\right)$, and each group of four purple arrows corresponds to a single electron localized on the phenyl groups belonging to the same metalloporphyrin. (b) Calculated molecular orbitals involving the edge-to face and (c) face-to-face $\pi$ stackings. 
Table 3. Calculated Energy for $\left(\mathrm{FeTPPbipy}_{2}\right)_{2}$ Dimers

\begin{tabular}{ccccc} 
dimer & $\begin{array}{c}\boldsymbol{\pi} \\
\text { interactions }\end{array}$ & $\begin{array}{c}\text { coupling } \\
\text { through } \pi \\
\text { interactions }\end{array}$ & $\begin{array}{c}\text { no. of unpaired } \\
\text { electrons per } \\
\text { dimer }\end{array}$ & $\begin{array}{c}\text { calculated energy } \\
\text { (hartree) }\end{array}$ \\
$\mathbf{1}$ & edge-to-face & yes & 2 & -8331.1805358 \\
$\mathbf{1}$ & edge-to-face & no & 4 & -8331.1309928 \\
$\mathbf{2}$ & face-to-face & yes & 2 & -8331.1814716 \\
$\mathbf{2}$ & face-to-face & no & 4 & -8331.1533709 \\
\hline
\end{tabular}

360 Self-Assembly of Neutral Radicals. As $\pi$ stacking is 361 extended on the (101) planes, extrapolation of the DFT 362 calculations to the $3 \mathrm{D}$ network can be done. As observed in 363 Figure $8 b, c$, the contribution of the phenyl molecular orbitals to $\pi$ 364 stacking is consistent with this extrapolation. First of all, the 365 electron acquired by the porphyrin could be thought of as 366 delocalized on the four phenyl groups. On the other hand, if 367 considering that magnetic measurements are consistent with the 368 presence of a value close to one unpaired electron per monomer, 369 the spin distribution proposed in Figure 8a could be a reasonable 370 explanation for the behavior of this compound. This spin 371 distribution is based on the occurrence of antiferromagnetic 372 coupling not only between electrons belonging to the metal 373 center and phenyl groups (as previously mentioned in the 374 Magnetic Measurements section) but also between phenyl elec375 trons localized on adjacent 1D polymers, as seen in Figure 8b,c. 376 In summary, identification of the localization of the acquired 377 electrons is the key point that supports the idea of neutral radicals 378 having been able to self-assemble, producing such a 3D framework.

\section{CONCLUSIONS}

380 The compound $\left(\left[\text { FeTPPbipy }^{\bullet}\right)_{n}\right.$ has been formed by the assembly 381 of metalloporphyrinic neutral radicals that have been formed 382 by one-electron reduction of the original $[\mathrm{FeTPP}]^{+}$cations, as sug383 gested by the presence of low-spin $\mathrm{Fe}^{\mathrm{III}}$ ions. The as-acquired 384 electrons are proposed to be paired in the molecular orbitals formed 385 by $\pi-\pi$ interactions between the phenyl groups of different $1 \mathrm{D}$ 386 polymers. The resulting packing is the first Fe-TPP-bipy 387 coordination network exhibiting $1 \mathrm{D}$ polymers.

\section{ASSOCIATED CONTENT}

389 S Supporting Information

390 ORTEP detail of the structure, IR and EPR spectra, X-ray 391 measurements, crystallographic data, and a CIF file for CCDC 392888109 . This material is available free of charge via the Internet at 393 http://pubs.acs.org.

\section{AUTHOR INFORMATION}

\section{Corresponding Author}

396 *E-mail: gotzone.barandika@ehu.es.

\section{Author Contributions}

398 The manuscript was written through contributions of all authors. 399 All authors have given approval to the final version of the 400 manuscript. All authors contributed equally.

\section{Notes}

402 The authors declare no competing financial interest.

\section{ACKNOWLEDGMENTS}

404 This work has been financially supported by the "Ministerio de 405 Ciencia e Innovación" (MAT2010-15375), the "Gobierno Vasco" 406 (Basque University System Research Groups, IT-630-13), and 407 UPV/EHU (UFI 11/15), which we gratefully acknowledge. SGIker 408 (UPV/EHU) technical support (MEC, GV/EJ, European Social
Fund) is gratefully acknowledged. The authors thank Dr. Fernando 409 Plazaola (UPV/EHU) for her help in interpreting the Mössbauer 410 spectra. A.F.-M. thanks the UPV/EHU for fellowships.

411

\section{REFERENCES}

412

(1) Beletskaya, I.; Tyurin, V. S.; Tsivadze, A. Y.; Guilard, R.; Stern, C. 413 Chem. Rev. 2009, 109, 1659-1713.

414

(2) Drain, C. M.; Varotto, A.; Radivojevic, I. Chem. Rev. 2009, 109, 415 $1630-1658$.

(3) Wang, C.; Xie, Z.; deKrafft, K. E.; Lin, W. J. Am. Chem. Soc. 2011, 417 $133,13445-13454$.

(4) Margelefsky, E. L.; Zeidan, R. K.; Davis, M. E. Chem. Soc. Rev. 2008, 419 37, $1118-1126$.

\section{0}

(5) Mola, J.; Mas-Marza, E.; Sala, X.; Romero, I.; Rodriguez, M.; Vinas, 421 C.; Parella, T.; Llobet, A. Angew. Chem., Int. Ed. 2008, 47, 5830-5832. 422

(6) Zou, C.; Wu, C.-D. Dalton Trans. 2012, 41, 3879-3888. 423

(7) Shultz, A. M.; Farha, O. K.; Hupp, J. T.; Nguyen, S. T. J. Am. Chem. 424 Soc. 2009, 131, 4204-4205.

(8) Gao, B.; Zhao, J.; Li, Y. J. Appl. Polym. Sci. 2011, 122, 406-416. 426

(9) Mohnani, S.; Bonifazi, D. Coord. Chem. Rev. 2010, 254, 2342- 427 2362. 428

(10) Zeitouny, J.; Aurisicchio, C.; Bonifazi, D.; De Zorzi, R.; Geremia, 429 S.; Bonini, M.; Palma, C.-A.; Samori, P.; Listorti, A.; Belbakra, A.; 430 Armaroli, N. J. Mater. Chem. 2009, 19, 4715-4724.

(11) Liu, C.-X.; Liu, Q.; Guo, C.-C.; Tan, Z. J. Porphyrins 432 Phthalocyanines 2010, 14, 825-831. 433

(12) Castro, K. A. D. F.; Halma, M.; Machado, G. S.; Ricci, G. P.; 434 Ucoski, G. M.; Ciuffi, K. J.; Nakagaki, S. J. Braz. Chem. Soc. 2010, 21, 435 $1329-1340$.

(13) Serwicka, E. M.; Poltowicz, J.; Bahranowski, K.; Olejniczak, Z.; 437 Jones, W. Appl. Catal., A 2004, 275, 9-14. 438

(14) Schuenemann, V.; Trautwein, A. X.; Rietjens, I. M. C. M.; 439 Boersma, M. G.; Veeger, C.; Mandon, D.; Weiss, R.; Bahl, K.; 440 Colapietro, C.; Piech, M.; Austin, R. N. Inorg. Chem. 1999, 38, 4901- 441 4905. 442

(15) Cooke, P. R.; Gilmartin, C.; Gray, G. W.; Lindsay Smith, J. R. J. 443 Chem. Soc., Perkin Trans. 2 1995, 2, 1573-1578. 444

(16) Hilal, H. S.; Kim, C.; Sito, M. L.; Schreiner, A. F. J. Mol. Catal. 445 1991, 64, 133-142.

(17) Garibay, S. J.; Stork, J. R.; Cohen, S. M. Prog. Inorg. Chem. 2009, 447 56, 335-378. 448

(18) Burnett, B. J.; Barron, P. M.; Choe, W. CrystEngComm 2012, 14, 449 3839-3846.

(19) Kumar, R. K.; Balasubramanian, S.; Goldberg, I. Chem. Commun. 451 1998, 1435-1436.

(20) Tsao, T.-B.; Lee, G.-H.; Yeh, C.-Y.; Peng, S.-M. Dalton Trans. 453 2003, 1465-1471.

(21) Kumar, D. K.; Das, A.; Dastidar, P. Inorg. Chem. 2007, 46, 7351- 455 7361.

(22) Diskin-Posner, Y.; Patra, G. K.; Goldberg, I. J. Chem. Soc., Dalton 457 Trans. 2001, 2775-2782.

(23) Wang, Q.-G.; Xie, Y.-S.; Zeng, F.-H.; Ng, S.-W.; Zhu, W.-H. Inorg 459 Chem. Commun. 2010, 13, 929-931. 460

(24) Burrell, A. K.; Officer, D. L.; Reid, D. C. W.; Wild, K. Y. Angew. 461 Chem., Int. Ed. 1998, 37, 114-117.

(25) Mikami, S.; Sugiura, K.-i.; Maruta, T.; Maeda, Y.; Ohba, M.; Usuki, 463 N.; Okawa, H.; Akutagawa, T.; Nisihara, S.; Nakamura, T.; Iwasaki, K.; 464 Miyazaki, N.; Hino, S.; Asato, E.; Miller, J. S.; Sakata, Y. J. Chem. Soc., 465 Dalton Trans. 2001, 448-455.

(26) Summerville, D. A.; Cohen, I. A.; Hatano, K.; Scheidt, W. R. Inorg. 467 Chem. 1978, 17, 2906-2910. 468

(27) Calderon-Casado, A.; Barandika, G.; Bazan, B.; Urtiaga, M.-K.; 469 Vallcorba, O.; Rius, J.; Miravittles, C.; Arriortua, M.-I. CrystEngComm 470 2011, 13, 6831-6838.

(28) Barandika, M. G.; Hernandez-Pino, M. L.; Urtiaga, M. K.; Cortes, 472 R.; Lezama, L.; Arriortua, M. I.; Rojo, T. J. Chem. Soc., Dalton Trans. 473 2000, 1469-1473. 
475 (29) Barandika, M. G.; Cortes, R.; Serna, Z.; Lezama, L.; Rojo, T.; 476 Urtiaga, M. K.; Arriortua, M. I. Chem. Commun. 2001, 45-46.

477 (30) de la Pinta, N.; Martin, S.; Urtiaga, M. K.; Barandika, M. G.; 478 Arriortua, M. I.; Lezama, L.; Madariaga, G.; Cortes, R. Inorg. Chem. 479 2010, 49, 10445-10454.

480 (31) Hernandez, M. L.; Urtiaga, M. K.; Barandika, M. G.; Cortes, R.; 481 Lezama, L.; de la Pinta, N.; Arriortua, M. I.; Rojo, T. J. Chem. Soc., Dalton 482 Trans. 2001, 3010-3014.

483 (32) Serna, Z. F.; Lezama, L.; Urtiaga, M. K.; Arriortua, M. I.; 484 Barandika, M. G.; Cortes, R.; Rojo, T. Angew. Chem., Int. Ed. 2000, 39, 485 344-347.

486 (33) Fidalgo-Marijuan, A.; Barandika, G.; Bazan, B.; Urtiaga, M.-K.; 487 Arriortua, M.-I. Polyhedron 2011, 30, 2711-2716.

488 (34) DeVries, L. D.; Choe, W. J. Chem. Crystallogr. 2009, 39, 229-240.

489 (35) Yinghua, W. J. Appl. Crystallogr. 1987, 20, 258-259.

490 (36) Sheldrick, G. M. Acta Crystallogr., Sect. A: Found. Crystallogr. 2008, 491 A64, 112-122.

492 (37) Scheidt, W. R.; Geiger, D. K.; Haller, K. J. J. Am. Chem. Soc. 1982, 493 104, 495-499.

494 (38) Saffari, J.; Khorasani-Motlagh, M.; Noroozifar, M. Synth. React. 495 Inorg., Met.-Org., Nano-Met. Chem. 2010, 40, 899-904.

496 (39) Mezger, M.; Hanack, M.; Hirsch, A.; Kleinwaechter, J.; Mangold, 497 K. M.; Subramanian, L. R. Chem. Ber. 1991, 124, 841-847.

498 (40) Jentzen, W.; Song, X.-Z.; Shelnutt, J. A. J. Phys. Chem. B 1997, 101, 499 1684-1699.

500 (41) Jentzen, W.; Ma, J.-G.; Shelnutt, J. A. Biophys. J. 1998, 74, 753501763.

502 (42) Ohgo, Y.; Hoshino, A.; Okamura, T.; Uekusa, H.; Hashizume, D.; 503 Ikezaki, A.; Nakamura, M. Inorg. Chem. 2007, 46, 8193-8207.

504 (43) Quinn, R.; Strouse, C. E.; Valentine, J. S. Inorg. Chem. 1983, 22, 505 3934-3940.

506 (44) Ikezaki, A.; Tukada, H.; Nakamura, M. Chem. Commun. 2008, $507 \quad 2257-2259$.

508 (45) Gans, P.; Buisson, G.; Duee, E.; Marchon, J. C.; Erler, B. S.; 509 Scholz, W. F.; Reed, C. A. J. Am. Chem. Soc. 1986, 108, 1223-1234.

510 (46) Ochiai, E.-i. Bioinorganic Chemistry: An Introduction; Allyn and 511 Bacon, Inc.: Boston, MA, 1977; Chapter 5.

512 (47) Frisch, M. J.; Trucks, G. W.; Schlegel, H. B.; Scuseria, G. E.; Robb, 513 M. A.; Cheeseman, J. R.; Montgomery, J. A., Jr.; Vreven, T.; Kudin, K. 514 N.; Burant, J. C.; Millam, J. M.; Iyengar, S. S.; Tomasi, J.; Barone, V.; 515 Mennucci, B.; Cossi, M.; Scalmani, G.; Rega, N.; Petersson, G. A.; 516 Nakatsuji, H.; Hada, M.; Ehara, M.; Toyota, K.; Fukuda, R.; Hasegawa, 517 J.; Ishida, M.; Nakajima, T.; Honda, Y.; Kitao, O.; Nakai, H.; Klene, M.; 518 Li, X.; Knox, J. E.; Hratchian, H. P.; Cross, J. B.; Bakken, V.; Adamo, C.; 519 Jaramillo, J.; Gomperts, R.; Stratmann, R. E.; Yazyev, O.; Austin, A. J.; 520 Cammi, R.; Pomelli, C.; Ochterski, J. W.; Ayala, P. Y.; Morokuma, K.; 521 Voth, G. A.; Salvador, P.; Dannenberg, J.J.; Zakrzewski, V. G.; Dapprich, 522 S.; Daniels, A. D.; Strain, M. C.; Farkas, O.; Malick, D. K.; Rabuck, A. D.; 523 Raghavachari, K.; Foresman, J. B.; Ortiz, J. V.; Cui, Q.; Baboul, A. G.; 524 Clifford, S.; Cioslowski, J.; Stefanov, B. B.; Liu, G.; Liashenko, A.; 525 Piskorz, P.; Komaromi, I.; Martin, R. L.; Fox, D. J.; Keith, T.; Al-Laham, 526 M. A.; Peng, C. Y.; Nanayakkara, A.; Challacombe, M.; Gill, P. M. W.; 527 Johnson, B.; Chen, W.; Wong, M. W.; Gonzalez, C.; Pople, J. A. Gaussian 528 03, revision D.02; Gaussian, Inc.: Wallingford, CT, 2004.

529 (48) Becke, A. D. J. Chem. Phys. 1993, 98, 5648-5652.

530 (49) Lee, C.; Yang, W.; Parr, R. G. Phys. Rev. B: Condens. Matter 1988, $53137,785-789$.

532 (50) Brand, R. A.; Lauer, J.; Herlach, D. M. J. Phys. F: Met. Phys. 1983, $53313,675-683$.

534 (51) Tsirel'son, V. G.; Antipin, M. Y.; Strel'tsov, V. A.; Ozerov, R. P.; 535 Struchkov, Y. T. Dokl. Akad. Nauk SSSR 1988, 298, 1137-1141.

536 (52) Ou, Z.; E, W.; Zhu, W.; Thordarson, P.; Sintic, P. J.; Crossley, M. 537 J.; Kadish, K. M. Inorg. Chem. 2007, 46, 10840-10849.

538 (53) Pereira, M. M.; Abreu, A. R.; Goncalves, N. P. F.; Calvete, M. J. F.; 539 Simoes, A. V. C.; Monteiro, C. J. P.; Arnaut, L. G.; Eusebio, M. E.; 540 Canotilho, J. Green Chem. 2012, 14, 1666-1672.

541 (54) Scheidt, W. R.; Brancato-Buentello, K. E.; Song, H.; Reddy, K. V.; 542 Cheng, B. Inorg. Chem. 1996, 35, 7500-7507.
"This document is the Accepted Manuscript version of a Published Work that appeared in final form in Inorganic Chemistry, copyright $($ ) American Chemical Society after peer review and technical editing by the publisher. To access the final edited and published work see http:// http://pubs.acs.org/doi/abs/10.1021/ic4007372." 